\title{
Health Politics in Periods of Economic Crises: Lessons from the Past Help Us Plan the Future
}

\section{Emmanouil Magiorkinis*}

Department of Hygiene, Epidemiology and Medical Statistics, Athens University Medical School, Salamina, Greece

\section{Introduction}

The interrelation between health politics, public health and economic crises is a field of intense scientific debate. Inevitably, economic crisis and recession poses a heavy burden on citizens and public health care system. On one hand, unemployed citizens are unable to afford health insurance due to loss of finance support, which leads to increased morbidity and mortality as a result of limited access to the health system. On the other hand, public health policies collapse under the growing loss of gross domestic product (GDP).

\section{Economic crises and public health in historical perspective}

Kirsty Walker in her paper published two years ago in the Historical Journal [1], reviews extensively the impact of economic crises on public health during the $20^{\text {th }}$ century. Although the results from various studies are controversial, it is more or less acceptable that economic crises challenged health systems in the past, especially in the developing world. The most recent example of the East Asian economic crisis in 1997-1998, as referred by Walker, had a huge impact on the Indonesia, whereas the US embargo in 1992 in Cuba resulted in significant public health deterioration.

\section{The current status and estimates}

The current economic crisis triggered by the meltdown of subprime mortgage industry in the US in the last four months of 2008, spread like an epidemic globally. All European economies have been hit hard, as one can notice by the attempts of the International Monetary Fund (IMF) to support Eastern European Countries, and more recently Ireland, Portugal and Greece. The World Health Organization, in 2009, stated that: "It is not yet clear what the current financial crisis will mean for low-income and emerging economies, but many predictions are highly pessimistic." [2]. Health is a global concern and a constitutional human right, whereas access to health care is a fundamental entitlement and responsibility of governments the world over. Dan Bednarz in the end of his article poses an interesting question about the future of health systems in periods of economic crisis: "The next set of questions to ask revolves around how to build stainable health systems in a contracting economy where increases in government funding cannot be expected. This is daunting (where as they would say in Detroit- the rubber meets the road) and I invite those with views and suggestions, as well as specific real-world problem situations, to share them with me" [3].

\section{Conclusions: planning for the future}

The ongoing economic crisis still takes its toll on the 'weak links' of the global economy. The need for more cost-effective studies in various fields of medicine is more imperative than ever; therapeutic guidelines should be based on such studies, which minimize cost without jeopardizing patients' health. Last but not least, the most important axis of public health policies should be the funding of studies on preventive medicine; the cost of prevention of various diseases with a high death toll in modern societies such as cancer and cardiovascular diseases is much lower than the cost of therapy and hospitalization. The importance of preventive medicine, after all, was stressed by the father of medicine, Hippocrates stating that prevention is better than cure.

\section{References}

1. Walker K (2010) Historical perspectives on economic crises and Health. The Historical Journal 53: 477-494.

2. WHO (2009) Impact on financial crisis on health: a truly global solution is needed.

3. Dan Bednarz (2010) Impacts of the economic crisis on public health, part II: Paradigms and the right questions.
*Corresponding author: Emmanouil Magiorkinis, Medical Doctor, Department of Hygiene, Epidemiology and Medical Statistics, Athens University Medical School, Salamina, Greece, E-mail: mayiork@med.uoa.gr

Received February 20, 2012; Accepted February 21, 2012; Published March 01, 2012

Citation: Magiorkinis E (2013) Health Politics in Periods of Economic Crises: Lessons from the Past Help Us Plan the Future. J Socialomics 2: e109. doi:10.4172/2167-0358.1000e109

Copyright: (ㅇ 2013 Magiorkinis E. This is an open-access article distributed under the terms of the Creative Commons Attribution License, which permits unrestricted use, distribution, and reproduction in any medium, provided the original author and source are credited. 